\title{
LAS PRÁCTICAS SOSTENIBLES DEL AVITURISMO COMUNITARIO EN LA LOCALIDAD DE USME
}

\author{
Jorge Alexander Mora Forero \\ jorge.moraf@uniminuto.edu \\ Uniminuto Virtual y Distancia \\ Leidy Arias Jiménez \\ Leidy.arias-j@uniminuto.edu.co \\ Uniminuto Virtual y Distancia \\ Angie Lorena Villa Galeano \\ Angie.villa@uniminuto.edu.co \\ Uniminuto Virtual y Distancia
}

\section{Resumen}

El turismo comunitario se caracteriza por ser una forma de autogestión de los recursos naturales y culturales, principalmente en los territorios rurales. Es una oportunidad para que muchas comunidades gestionen sus recursos turísticos de forma autónoma. Esta forma de administración tiene en cuenta diversas formas entre las que se destaca el aviturismo comunitario. Esta forma de turismo se ha constituido una práctica frecuente debido a la gran riqueza ornitológica que posee el territorio colombiano. Para esta investigación se analiza la gestión del aviturismo desde una perspectiva comunitaria, es decir como apropiación social de los anfitriones rurales en el territorio colombiano. Este análisis describe la gestión social y ambiental de dos iniciativas turísticas comunitarias de la Localidad de Usme en Bogotá, este estudio es social y ambiental que se realizó a través de varios trabajos de campo y entrevistas estructuradas con los líderes comunitarios. Los resultados se obtienen luego de entrevistas, donde se describen las prácticas turísticas que tienen las comunidades desde un punto de vista social y ambiental. Allí, se evidencia la gestión comunitaria del turismo y como los paisajes naturales y las especies son aprovechadas de forma sostenible por las comunidades. En conclusión, el aviturismo comunitario es una herramienta que permite alcanzar los Objetivos de Desarrollo Sostenible (ODS), desde un desarrollo social y ambiental en las comunidades, aunque hay varios aspectos en los que las comunidades deben mejorar.

Palabras clave

Aviturismo, turismo comunitario, turismo sostenible y aviturismo 


\section{Introducción}

El turismo comunitario se ha convertido en la actualidad como una oportunidad para que las comunidades puedan autogestionar los recursos naturales del territorio, y así obtener un ingreso económico. Además, Colombia es un país con una biodiversidad única en el mundo, adicional ocupa el primer en el mundo con la mayor cantidad de aves registradas. Esto hace que los habitantes de las áreas rurales tengan a su disposición este gran inventario de especies ornitológicas. De ahí, que se gestione el aviturismo comunitario por los campesinos de las áreas rurales.

Pues bien, el aviturismo comunitario se caracteriza por lograr una apropiación de los recursos naturales por los habitantes del territorio rural. Para lograr entender mejor este concepto se realiza una Investigación de Acción Participativa, a través de diversas jornadas de trabajo con las comunidades con el fin de detallar las prácticas comunitarias y ambientales en la gestión del aviturismo comunitario. Esto con el fin de aportar al desarrollo investigativo del aviturismo comunitario, teniendo en cuenta que son casi nulas las investigaciones de este concepto en el país. Es importante describir la realidad de las comunidades y reconocer gestión turística; esto permite enseñar la realidad de estas iniciativas en el territorio rural colombiano.

Es fundamental aportar al desarrollo científico del aviturismo desde una perspectiva de la comunidad, teniendo en cuenta que son pocas las investigaciones en esta materia. A pesar de que la Covid 19 en el 2020 ha detenido el turismo en el país, es importante indicar en el país esta 
actividad promete ser un eje dinamizador para el país (Mora, Yamova y Murtuzalieva, 2019: 508).

Ahora bien, si se analiza el turismo en el país, en los últimos cinco años ha tenido un crecimiento sostenido de dos dígitos, cifra que no es nada despreciable si se compara con el promedio mundial (Mora y Motato, 2019: 71). Es por ello, que esta investigación describe nuevas formas de gestión turística que se van desarrollando en el territorio nacional, adicional esto permite reconocer la sostenibilidad y los aportes de estas iniciativas que a pesar de desarrollarse a pequeña escala son un ejemplo de gran aporte para el desarrollo de nuevas prácticas y así alcanzar las metas de turismo sostenible que se ha propuesto la Organización de las Naciones Unidas para el 2030.

Para entender mejor el aviturismo comunitario, se realizó un estudio de caso en dos comunidades que ofertan servicios turísticos en la localidad de Usme en Bogotá. El objetivo de esta investigación es reconocer la gestión ambiental y comunitarias en el territorio rural de Usme, debido a que allí se ofertan actividades turísticas rurales y cuenta con un gran escenario como lo es el Agroparque Los Soches.

Pues bien, para entender mejor este estudio, se propone la siguiente pregunta de investigación ¿Cuáles son las prácticas ambientales y sociales en gestión del aviturismo comunitario en las comunidades rurales de Usme? Este interrogante permite analizar la gestión de un turismo sostenible analizando la forma en que este se relaciona con los Objetivos de Desarrollo Sostenible (ODS). Teniendo en cuenta que tales objetivos en síntesis integran tres aspectos el social, ambiental y económico. Priorizando "la lucha contra la pobreza 
y el hambre, pero con un fuerte anclaje en la defensa de los derechos humanos, la igualdad de género y el empoderamiento de las mujeres, abordando la reducción de las desigualdades entre otros" (Gil, 2018: 108).

\section{Marco teórico}

El turismo tiene una serie de tipologías y formas, dado su enfoque multidisciplinar, por ello, es importante reconocer las diferentes posturas que presentan los distintos autores que han abordado el turismo. Este apartado evidencia tres aspectos, el turismo comunitario, el aviturismo y el turismo sostenible; de este modo se describen los apartados teóricos con el fin de entender el constructo del concepto aviturismo comunitario el cual es un concepto emergente que se establece como un elemento que reúne los tres elementos anteriormente descritos.

\section{Turismo sostenible}

Cuando se incorporan los ODS a la industria actividad, se deben tener en cuenta varios aspectos. Más allá del medio ambiente, "el turismo sostenible debe reportar también un alto grado de satisfacción a los turistas y representar para ellos una experiencia significativa, que los haga más conscientes de los problemas de la sostenibilidad y fomente en ellos unas prácticas turísticas sostenibles" (OMT, 2018). El turismo sostenible tiene orígenes en el significado del desarrollo sostenible. Existen múltiples conceptos de desarrollo, la mayoría orientados al crecimiento y riqueza económica. Incluso, todavía hoy, se entiende el desarrollo como 
crecimiento económico. No obstante, nace el concepto de desarrollo económico social y es allí donde se comprende que el desarrollo no solo es ambiental, sino que también tiene en cuenta el nivel de vida de la población (Acerenza, 2013).

Pues bien, el turismo sostenible se reconoce como una "actividad que concilia la equidad social, la preservación del patrimonio natural y cultural en determinada población. Se basa en el desarrollo de actividades que garanticen la satisfacción de las necesidades de las actuales generaciones sin poner en riesgo las de las generaciones futuras (Mora y Motato, 2019: 149).

Como se puede apreciar el turismo es un bien adquirido por la sociedad y se incorpora como un área de desarrollo (Acerenza, 2012). De este modo, se propende reconocer los lineamientos que establecen las organizaciones adscritas a las Naciones Unidas y su relación con el turismo comunitario. El turismo de naturaleza está relacionado con el turismo sostenible, y las prácticas en entornos naturales, su biodiversidad y el involucramiento de la población perteneciente al área determinada (Quintana, 2017).

\section{Aviturismo}

Actualmente el aviturismo se comprende como una actividad de contemplación de especies alrededor del mundo, en la cual Colombia ocupa un lugar privilegiado por la gran cantidad taxonómica que registra frente a otros países con alrededor de 1912 especies y cuenta con 84 especies endémicas y casi endémicas (Ayerbe, 2018). Además, 
se tiene por comprendido que después del acuerdo del posconflicto en el año 2016 el sector turístico ha tenido un mayor auge en el ecoturismo, pero también se debe comprender que se debe cumplir con normas de sostenibilidad y buenas prácticas (Ocampo y Winton, 2017).

Se da por comprendido que la observación de aves emerge en la década de los cuarenta en países como Inglaterra y Estados Unidos y donde la actividad es practicada tanto en jóvenes como adultos según en un estudio realizado que determina los principales factores que influyen para realizar actividades de contemplación de fauna silvestre y observación de avifauna en Norteamérica (Cooper y otros, 2015). Igualmente es evidente que no se necesita tener demasiada experiencia en el tema de las aves, si no por el contrario es un espacio donde las personas pueden sentir gusto y curiosidad por conocer más a fondo el mundo de las aves y que sin importar se puede compartir conocimiento por medio de la experiencia educativa que transmiten biólogos, ornitólogos y especialistas en el tema (Mora y García, 2019).

Según Bello Umaña y Azofeifa Rojas (2019), en el aviturismo se aplican diferentes maneras para realizar el ejercicio de la observación y descubrir diferentes especies de aves, esto se hace gracias a personas con conocimiento empírico, experimentadas y profesionales que se han dedicado a el aviturismo. López (2008) indica que, por medio del análisis de las tipologías del turismo al momento de presentar una serie de estudios, donde se logra evidenciar la percepción del turista en el ecoturismo por medio de la observación de aves. Por otro lado, De Juan Alonso (2006) plantea que la ornitología atrae este tipo de turismo gracias a la cantidad de especies de aves que se pueden encontrar en los 
distintos sitios naturales con los cuales cuenta el territorio nacional y la actividad que se practica sin duda es de solo observación o según en términos como contemplación. También agrega que el guía debe prestar un servicio de calidad para que los turistas logren mantener la atención y la participación, y de esta manera mejorar las oportunidades laborales por medio de una economía sostenible.

Turismo comunitario

Algunos ODS tienen una baja asociación con el turismo comunitario, como es el caso del hambre cero. Por otro lado, en algunos objetivos existe una relación intrínseca con el turismo comunitario como lo son: fin de la pobreza, ciudades y comunidades sostenibles y acción por el clima (Mora y Bohórquez, 2018). El Turismo comunitario emerge en Colombia como una opción de desarrollo rural después del conflicto armado que tuvo lugar durante 50 años en el país (Mora,Yamova y Murtuzalieva, 2019). Si bien el Turismo comunitario trae múltiples beneficios a las comunidades se debe gestionar correctamente para que cumpla con los propósitos que se abarcan. Existen ciertos elementos que contribuyen y complementan el buen desarrollo del Turismo comunitario en los destinos como lo es la sostenibilidad y el Turismo responsable ya que estos factores influyen en la percepción de calidad de vida y bienestar en las comunidades (Mathew y Sreejesh, 2017).

La percepción de los impactos positivos siendo resultado del turismo impulsa a la comunidad a apoyar el desarrollo turístico y así 
mismo a participar de él, si por el contrario los impactos son mayormente negativos la comunidad no estará interesada en cooperar (Rasoolimanesh y otros, 2017). Respecto a la localidad de Usme el turismo comunitario en las áreas rurales ha estado en auge en los últimos años, donde los campesinos ofertan a los turistas el proceso que se necesita para el cultivo de sus productos y lo complementan con la gastronomía típica de la región, entre otros (Burgos, 2017).

\section{Aviturismo comunitario}

El aviturismo comunitario puede convertirse en una estrategia que contribuya al desarrollo regional, a partir de los beneficios económicos y sociales que ayudan a salvaguardar el hábitat y la biodiversidad del territorio (Carrillo, Enríquez y Meléndez, 2017). También, se puede aseverar que esta actividad se orienta la generación de productos turísticos que involucren a la comunidad local. De este modo, se pueden abordan de forma positiva las repercusiones económicas, sociales y ambientales de acuerdo la incorporación de los ODS en el turismo.

El aviturismo comunitario son las actividades que realizan los avistadores de aves o turistas en las comunidades, donde los anfitriones del territorio ven la oportunidad apropiarse del conocimiento de las especies ornitológicas y así desarrollar y prestar servicios turísticos como un sustento complementario a su economía local. Por ello, debe existir una integración y distribución, así como tener el personal capacitado (Mora y Otros, 2020: 162). 


\section{Metodología}

Para esta investigación se analizó una comunidad rural en los aspectos sociales y ambientales. Esto se describirá desde un aspecto comunitario, es decir desde la autogestión local de las comunidades. Pare ello, se realizó una investigación de acción participativa (IAP), la cual aporta al desarrollo del turismo a través de las ciencias humanas y aplicadas. El trabajo de campo se realizó a través de varias visitas durante 2019, con el fin describir la forma en que estas comunidades han abordado el aviturismo. Allí se realizaron dos evaluaciones una con el fin de revisar los aspectos sociales y de dar una descripción de los aspectos ambientales en la gestión del aviturismo.

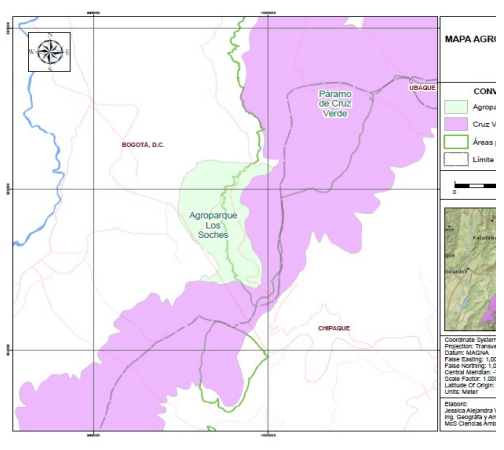

Ilustración 1 Ubicación Agroparque los Soche

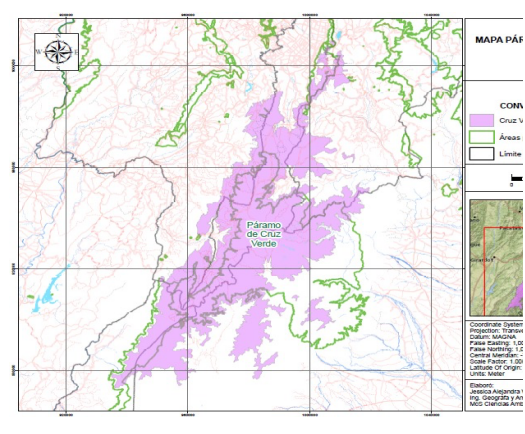

Ilustración 2 Ubicación Páramo de Cruz Vede

El trabajo de campo se dio a través de tres fases, primero se realizó un acercamiento; con el fin de realizar un recorrido guiado y un ejercicio de observación etnográfica participativa (Angrosino, 2012), allí se observó el paisaje turístico. La segunda con el fin de realizar una jornada de avistamiento de aves en el Agroparque Los Soches, el cual se encuentra en Usme tal y como se puede apreciar en la llustración 1. 
La tercera con el fin de realizar una jornada de avistamiento de las aves en el páramo de Cruz Verde que se encuentra adyacente al Agroparque Los Soches (Ilustración 2) que cuenta con el apoyo de un biólogo experto en especies ornitorrincas que la comunidad contrató. Los trabajos de campo permitieron abordar a las comunidades y ahondar acerca de la forma en la que gestionan el aviturismo. En todas las fases se realizaron entrevistas con la comunidad.

\section{Resultados}

Este epígrafe es el resultado del trabajo de campo, la información acá planteada se obtuvo de los líderes comunitarios. Es importante hacer hincapié en que este estudio se obtiene luego de recopilar entrevistas, de acuerdo con opiniones y puntos de vista.

Esta iniciativa nace de un grupo de campesinos, que se organizaron para liderar el proyecto que daría origen al Agroparque Los Soches, lo cual ocasionó una reducción en los precios de los terrenos, pero logrando que fuera declarado como territorio rural en lugar de expansión urbana. Lo anterior, se evidencia que la comunidad pasó por un proceso de presión para que terminaran vendiendo sus tierras y con esto, la administración local lograra el proyecto de expansión urbana de la ciudad. La condición de Agroparque tiene como finalidad que la comunidad de la vereda Los Soches conserve su modo de vida tradicional, pero adoptando características especiales en su proceso productivo, para dar cabida a nuevas actividades como por ejemplo el desarrollo del turismo. 
Registro de aves encontradas en las jornadas de avistamiento de aves

Tabla 1. Listado de especies encontradas en los recorridos por las zonas de estudio

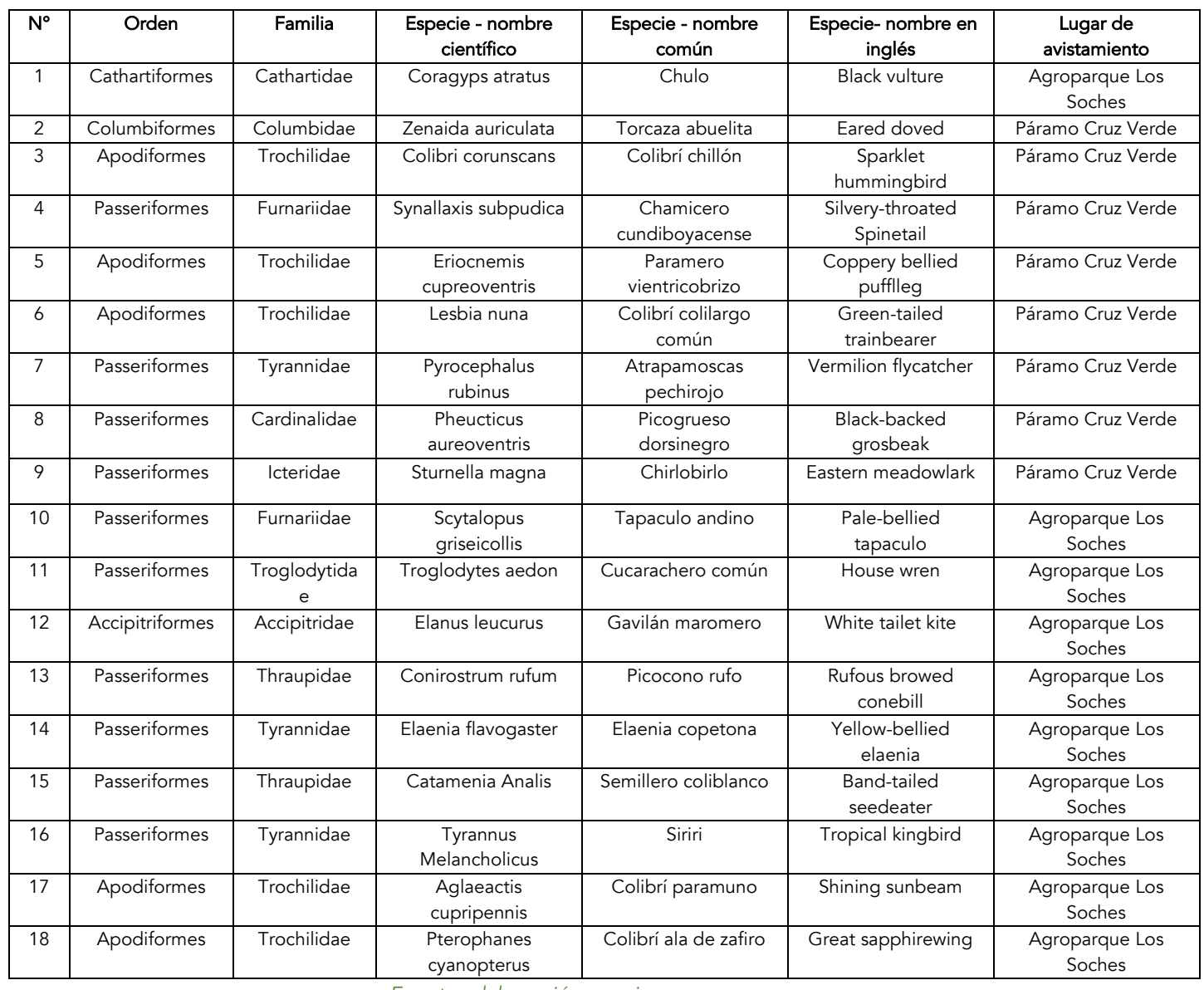

Fuente: elaboración propia.

\section{Aportes del aviturismo a la comunidad local}

Gracias a la aplicación del aviturismo comunitario, las comunidades generan un sentido de unión y trabajo en conjunto, que les permite desarrollarse en un ambiente social propicio y vivir en fraternidad con todos aquellos que conforman el entorno. Adicional a esto, se presenta una interacción social entre la comunidad local, y los 
avituristas que visitan el territorio, lo que ocasiona un intercambio de culturas, conocimientos y relatos, que además de permitir conocer el uno del otro, también aumentan la experiencia de los turistas, al tiempo que se genera conciencia desde el pensamiento rural, sobre la importancia de preservar las especies de aves y se le transmite el conocimiento sobre la avifauna que podrán encontrar.

Por otra parte, en el ámbito social, la comunidad comienza a desenvolverse en diferentes ámbitos, ajenos a su territorio pero que pueden contribuir en gran medida porque aportan y generan ideas para mejorar la práctica del aviturismo.

\section{Buenas prácticas sociales en aviturismo}

El aviturismo comunitario genera necesariamente una interacción variada, esde suma importancia saber escuchar, hablar e interrelacionarse. La comunidad sostiene relaciones oportunas entre sí y las comparte con los visitantes. Esto queda en evidencia cuando los grupos de turistas están en su actividad dentro de la vereda, y se encuentran con algún miembro de la comunidad, este los saluda, y así mismo lo hace quien se encuentra guiando al grupo.

La vereda Los Soches cuenta con c muy buena comunicación y las personas mantienen buenas relaciones entre ellas. Existe un principio de respeto por el prójimo y por sus actividades económicas. Allí se dedican a labores campesinas, sin embargo, solo algunos han acogido al turismo como actividad económica adicional, a pesar de ello, quienes no están 
interesados en formar parte del turismo respetan a quienes sí lo hacen y viceversa.

\section{Conservación de avifauna}

El aviturismo comunitario ayuda considerablemente a la conservación de las especies de aves, ya que genera un conocimiento más específico de las características y la importancia que tienen en los ecosistemas, a la vez que se reconocen como parte del paisaje y de la cultura local. Por ejemplo, el caso del apodo que se le tiene a una de las especies de aves por su canto, el "comprapán" (Grallaria ruficapilla) es uno de los pájaros más comunes que se escuchan especialmente en zonas de arbustos y rastrojos en horas de la mañana cuando los habitantes del lugar están preparándose para desayunar, y el sonido que emite y la hora en que se le escucha, ya lo hace representativo para las personas donde se dice que su canto hace referencia a decir "compra pan". De igual manera, se logra identificar que la comunidad se siente orgullosa de la diversidad y cantidad de aves que alberga su territorio, donde han aprendido datos importantes a través del aviturismo comunitario para conservación de la avifauna y por esta razón velan por su bienestar.

Identificación de impactos ambientales

A través del tiempo, la comunidad ha adquirido una serie de conocimientos y han desarrollado una serie de técnicas que les ha 
permitido ser consciente de los impactos ambientales positivos y negativos de cada una de las actividades que se realizan; desde el manejo de la tierra, la crianza de animales y el consumo de recursos naturales en sus labores campesinas, hasta la práctica del turismo. La comunidad está muy comprometida y atenta a identificar y mitigar aquellos impactos negativos como consecuencia que se puedan generar y cómo hacer mejorar de forma gradual. Por ejemplo, en el cultivo de sus tierras, utilizan elementos amigables con el medio ambiente, para poder garantizar la sostenibilidad y no deteriorar sus campos, así como también hacen buen uso de los desperdicios y mantienen un proceso sano de crianza de animales, para evitar contaminación y enfermedades.

Por otra parte, en la práctica del turismo comunitario, se respetan los senderos delimitados para mitigar el impacto del ser humano en el territorio y permitir la continuidad de su desarrollo, así como también se tiene en cuenta la capacidad de carga; la comunidad es consciente de la problemática que se vive por culpa del turismo depredador, que acaba con los atractivos naturales, y por eso, procuran contribuir en la mayor medida posible a la práctica de un turismo responsable con el medio ambiente.

Los habitantes del territorio brindan charlas para concientizar al turista y tienen perfecto conocimiento sobre el respeto por la naturaleza, desde actos sencillos como no arrojar basura, ahorrar y reciclar agua, no dañar la flora ni la fauna, hasta el uso de energías renovables permite un conocimiento sólido en el no dejar rastro o manejo adecuado de la huella de carbón. 


\section{Buenas prácticas ambientales en aviturismo}

La comunidad que se encuentra dedicada al aviturismo está siempre en procesos de capacitación para poder aplicar los conocimientos adquiridos al desarrollo de esta actividad. En este caso, el líder comunitario Guillermo Villalba, se encuentra vinculado a una agencia de viajes operadora mediante la cual, participa activamente en distintos eventos educativos, y también asiste a la Vitrina Turística para dar a conocer su trabajo, lo cual permite dar un reconocimiento a la zona y de igual manera mostrar sostenibilidad en el turismo local.

La participación y asistencia que ha tenido en los diferentes eventos relacionados con turismo sostenible, le han permitido aplicar buenas prácticas económicas, sociales y medioambientales desde el aviturismo comunitario, al mismo tiempo que las comparte con todos los que se unen a su causa. Dentro de las prácticas que se realizan, está la delimitación del territorio, la preservación del entorno natural, el cuidado de las especies, el agua, y las prácticas de turismo sostenible en general.

\section{Conclusiones}

Se identifica el potencial con el cual cuenta el Agroparque Los Soches y el Páramo Cruz Verde para realizar las jornadas de avistamiento de aves. Además, se puede ver el valor agregado que brinda la comunidad por medio del aprendizaje autodidacta, el cual es transmitido hacia el turista. También se resalta que esta forma de 
turismo está en una fase implementación, por lo cual tiene un gran potencial para mejorar estas prácticas. Se pudo evidenciar y reconocer que el aviturismo comunitario es una gran oportunidad para el desarrollo de estas comunidades. Sin embargo, se debe informar y enseñar a las comunidades sobre los conceptos de sostenibilidad, turismo comunitario, entre otros.

En la localidad de Usme el turismo comunitario ha tenido auge en los últimos años, pero hace falta acompañamiento para poder formalizar las actividades de turismo comunitario que ellos ofertan. Las comunidades deben ser conscientes de su entorno e identificar como el turismo comunitario puede aportar a su comunidad.

Se evidencia que el impacto en el ecosistema es mínimo debido a que la comunidad tiene buenas prácticas ambientales. Por ello, se recomienda a la comunidad potencializar este producto turístico.

Es importante afirmar que a pesar de que el aviturismo sea una actividad de pequeña escala, debido a que por lo general los grupos para esta actividad no exceden las ocho personas, por temas de sostenibilidad, se proyecta como una práctica que aporta a las comunidades. Es importante, indicar que los ingresos económicos de la actividad turísticas aportan no solo al desarrollo económico endógeno, sino que a su vez estos aspectos impactan de forma positiva a la comunidad puesto que no hay flujos masivos del turismo, lo cual hace que desarrolle el turismo de forma armónica con la comunidad y el medio ambiente.

Es importante, reconocer que el aviturismo comunitario se desarrolla en pocas ocasiones, lo que evidencia que hay muchos aspectos por 
mejorar y también hay una gran proyección, debido a que el turismo que se desarrolla en esta localidad está más orientado hacia el ecoturismo, lo cual permite que esta comunidad incorpore nuevos productos turísticos lo cual aporta a la innovación y se podría afirmar que a la consolidación de un turismo en la región.

En conclusión, son bastante positivos los impactos del aviturismo en la comunidad, si se analiza desde la visión de la ONU para alcanzar los ODS. En términos generales son muchos los beneficios de esta actividad al desarrollo social y ambiental. De igual forma, se recomienda que la comunidad continúe en la mejora de la infraestructura turística del lugar. También, es importante la formación de los guías de turismo, quienes deben estar en constante capacitación no solo en materia ornitológica, sino en otros aspectos propios del aviturismo como es el caso del bilingüismo, dado que este es un factor de éxito para el desarrollo de los productos turísticos basados en aves.

\section{Referencias}

Acerenza, M. Á. (2013). Desarrollo Sostenible y Gestión del Turismo. México: Trillas Ayerbe, F (2018). Guía ilustrada de la avifauna colombiana. Bogotá: Editorial WCS.

Bello Umaña, Y. G y Azofeifa Rojas, I. (2019). Propuesta de aprovechamiento aviturístico para las comunidades rodeito, el triunfo y parcelas de Santa María De Liberia, Guanacaste, Costa Rica, 2017-2019 (tesis de doctorado). Universidad de Costa Rica, Guanacaste.

Burgos Doria, R. (2016). El turismo comunitario como iniciativa de desarrollo local: Caso localidades de Ciudad Bolívar y Usme zona rural de Bogotá. Hallazgos, 13(26), 193-214.

Cárdenas, D. A., Byrd, E. T., \& Duffy, L. N. (2015). An exploratory study of community awareness of impacts and agreement to sustainable tourism development principles. Tourism and Hospitality Research, 15(4), 254-266.

Carrillo, M., Enríquez, P., y Meléndez, A. (2017). Gestión comunitaria y potencial del aviturismo en el Centro de Ecoturismo Sustentable El Madresal, Chiapas, México. El periplo 
sustentable, (33), 564-604

De Juan Alonso, J. M. (2006). El turismo ornitológico: concepto y mercados. Referencias al destino Extremadura. Estudios turísticos, 169, 165-182. Recuperado de https://dialnet.unirioja.es/servlet/articulo?codigo $=2298448$

Gil, C. G. (2018). Objetivos de Desarrollo Sostenible (ODS): una revisión crítica. Papeles de relaciones ecosociales y cambio global,(140), 107-118.

López Roig, J. (2008). El turismo ornitológico en el marco del postfordismo, una aproximación teórico-conceptual. Cuadernos de Turismo, (21), 85-111. Recuperado de: https://revistas.um.es/turismo/article/view/25001

Mathew, P. V., \& Sreejesh, S. (2017). Impact of responsible tourism on destination sustainability and quality of life of community in tourism destinations. Journal of Hospitality and Tourism Management, 31, 83-89.

Mora Forero, J. A., \& Bohórquez Patiño, L. M. (2018). El turismo rural comunitario ¿ Una oportunidad en el posconflicto colombiano?. Riturem 2 (2), 49-59

Mora, J. A., Yamova, O., \& Murtuzalieva, T. (2019). Community-Based Tourism as the Leading Approach to the Rural Development. In Sustainable Leadership for Entrepreneurs and Academics (pp. 503-510). Springer, Cham.

Mora Forero, J.A., Motato Ramírez, J.W. (2019). Turismo Comunitario en Colombia Desarrollo social y sostenibilidad. Bogotá: Corporación Universitaria Minuto de Dios

Mora, Forero J.A. \& García, Ramírez N. A. (2019). Potencialidad del aviturismo para el desarrollo de iniciativas comunitarias en Cumaral Meta (Colombia). Riturem, 3 (2), 84112.

Mora Forero, J.A.,Bohórquez Patiño, L.A., Pérez Rodríguez, A.C., Amaya Cadena, J.A., Martínez Neira, Y.A., Rivera Fiquitiva, J., Rincón Bravo, M.E., Tequia Peralta, A.Y., Arias Jiménez, L., (2020).Aviturismo Comunitario en los páramos de Cundinamarca. Bogotá: Corporación Universitaria Minuto de Dios

Ocampo-Peñuela, N., \& Winton, R. S. (2017). Economic and conservation potential of birdwatching tourism in post conflict Colombia. Tropical Conservation Science, 10, 1940082917733862.

OMT. (2018). Sustainable Development of Tourism. Recuperado de: http://sdt.unwto.org/es/ content/definición

Quintana, V. M. (2017). El turismo de naturaleza: un producto turístico sostenible. Arbor, 193 (785), 396. 